\title{
The Angelina effect: immediate reach, grasp, and impact of going public
}

\author{
Dina L.G. Borzekowski, EdD', Yue Guan, ScM², Katherine C. Smith, PhD², Lori H. Erby, $\mathrm{PhD}^{2}$ and \\ Debra L. Roter, $\mathrm{DrPH}^{2}$
}

\begin{abstract}
Background: In May 2013, Angelina Jolie revealed in a New York Times opinion piece that she had undergone a preventive double mastectomy because she had a family history of cancer and carried a rare mutation of the $B R C A 1$ gene. Media coverage has been extensive, but it is not obvious what messages the public took from this personal health story.
\end{abstract}

Methods: We conducted a survey with a representative national online panel of 2,572 adults. Participants described their awareness and identified information sources for the Angelina Jolie news story. They also reported their understanding, reactions, perceptions, and subsequent activities related to the story. We asked questions pertaining to personal and societal breast cancer risk and hypothetical questions regarding preventive surgery if the respondent or a family member were in the same position as Ms Jolie. Demographic information was collected, as was family risk for breast and ovarian cancer, and a gauge of numeracy.
Results: While three of four Americans were aware of Angelina Jolie's double mastectomy, fewer than $10 \%$ of respondents had the information necessary to accurately interpret Ms Jolie's risk of developing cancer relative to a woman unaffected by the BRCA gene mutation. Awareness of the Angelina Jolie story was not associated with improved understanding.

Conclusion: While celebrities can bring heightened awareness to health issues, there is a need for these messages to be accompanied by more purposeful communication efforts to assist the public in understanding and using the complex diagnostic and treatment information that these stories convey.

Genet Med advance online publication 19 December 2013

Key Words: breast cancer; celebrity health narratives; $B R A C 1 / 2$; health communication

\section{INTRODUCTION}

When celebrities reveal health narratives, their stories have the potential to stimulate public interest and awareness of illness or medical procedures, inspire others to face similar medical issues, and promote public health policy. ${ }^{1,2}$ Media coverage of celebrity cancer experiences has been shown to impact health service utilization and adherence to preventive health guidelines. ${ }^{1,3-5}$ The influence of celebrity health narratives differs depending on audience characteristics. One study has shown a stronger impact of celebrity health narratives among the less educated and those who share demographic characteristics with the celebrity ${ }^{6}$; another study has suggested that an emotional involvement with the celebrity may be influential. ${ }^{7}$ Interestingly, coverage of celebrity health events is not universally associated with improved public health outcomes ${ }^{8,9}$; sometimes wrong, misleading, or alarming information is communicated. ${ }^{10}$ Moreover, subgroups can interpret and utilize appropriate health messages in unexpected ways. ${ }^{9}$

On 14 May 2013, actress, director, and humanitarian Angelina Jolie described in an opinion piece in The New York Times that she had recently undergone a prophylactic double mastectomy. Through genetic testing, Ms Jolie learned that she carried a rare $B R C A 1$ gene mutation and publically disclosed that her doctors estimated her risk of developing breast cancer to be $87 \%$. She went on to say that her breast cancer risk was now reduced to less than $5 \%$ by undergoing the breast surgery. In her commentary, Ms Jolie noted that only a fraction of breast cancers result from the inherited gene mutation but concluded that access to gene testing and lifesaving preventive treatment should be a priority for all women. The story was featured in news and entertainment media of all kinds; Ms Jolie's picture appeared on the cover of People magazine on two consecutive weeks following her revelation (15 May 2013 and 22 May 2013) and TIME magazine (27 May 2013) as well as a host of European and Asian periodicals. In Britain, Jolie's picture appeared on the front page of every national newspaper immediately following her disclosure. ${ }^{11}$

Given the intense media attention, this study was designed to examine immediate recall and public reaction to the story. We asked whether the typical American adult recalled the Angelina Jolie story, what elements of the story they retained, and how they understood and perceived what was described by and about this celebrity. We were especially interested in the public's ability to distinguish the genetic context of Angelina Jolie's risk of breast cancer from the lower risk that characterizes the vast majority of women who do not carry a $B R C A$ mutation. We also wondered about the extent to which exposure to

${ }^{1}$ Department of Behavioral and Community Health, School of Public Health, University of Maryland, College Park, Maryland, USA; ${ }^{2}$ Department of Health, Behavior, and Society, Bloomberg School of Public Health, Johns Hopkins University, Baltimore, Maryland, USA. Correspondence: Dina Borzekowski (dborzeko@umd.edu) 
the story affected respondents' self-rated breast/ovarian cancer risk in light of their family history. Finally, we were interested in the immediate impact of the story on information seeking and health discussions with family, genetic counselors and other health practitioners, cancer-related anxiety, and initiation of cancer-related preventive behaviors. In order to assess the immediate impact of the story on these questions, we designed and launched a rapid response survey within 3 weeks of Angelina Jolie's New York Times commentary.

\section{MATERIALS AND METHODS}

The study survey was conducted online within the United States between 3 June 2013 and 5 June 2013 among 2,572 adults (aged 18 years and older) by Harris Interactive on behalf of Johns Hopkins School of Public Health via its Quick Query product. The questions regarding Angelina Jolie and her announcement were included as part of Harris' routine omnibus survey that includes questions from multiple research initiatives. Omnibus survey respondents are recruited to participate regularly in research. As a collective, the respondents are intended to reflect the national population (considering age, sex, income, race, education, and region). To ensure representativeness, Harris employs a two-stage approach to respondent inclusion in the Omnibus poll. In stage 1, the outgoing sample is balanced demographically (based on the demographic factors including age, sex, income, race, education, and region), and incoming data are monitored against known targets for these variables according to the US Census Bureau's 2012 Current Population Survey. This ensures that data can be weighted to these targets without extreme weighting. In stage 2, Harris weights the data on demographic variables (age, sex, income, race, education, and region), in addition to a propensity score variable. This process is intended to adjust for attitudinal and behavioral factors that may differ between the sample group participants who participate in online surveys and those who do not. The Johns Hopkins Bloomberg School of Public Health Institutional Review Board determined that the research protocol for this study was exempt.

To facilitate the survey's rapid implementation and budget restrictions, we were limited to 12 questions. Although most of our items were based on previous measures, some modification was made for the sake of efficiency and format. For the most part, participants were asked to endorse responses from a list of multiple options, and we used only a few openended responses. Readers can see the complete survey in the Supplementary Appendix online.

Besides sociodemographic variables, participants were asked if they had read, heard, or seen any Angelina Jolie stories in the previous 3 weeks. The survey used a skip pattern, so only participants who accurately checked that Ms Jolie "had surgery (double mastectomy) to reduce her risk of breast cancer" were prompted to describe their information sources, attitudes toward the story, and understanding of Jolie's self-reported lifetime risk of developing breast cancer.

All participants, regardless of whether they were aware of Ms Jolie's surgery, answered general questions about their family history of breast and ovarian cancer, awareness of the proportion of cancers related to BRCA mutations, and the average woman's risk of developing breast cancer if she does not have the BRCA mutation. We also asked if respondents had engaged in any health-seeking activities related to breast or ovarian cancer in the past 3 weeks.

Using an approach derived from that used in the Health Information National Trends Survey, ${ }^{12}$ family history of breast and ovarian cancer was based on the participant's identification of the number of first (self, mother, father, son, daughter, sister, brother, and father), second (aunt, uncle, nephew, and niece), and third (cousin) degree relatives reported to have breast or ovarian cancer. This way of assessing family history is consistent with models of family risk assessment that focused on personal cancer history and the number of affected paternal and maternal first, second, and third degree of relatives. ${ }^{13-15}$

Using the format suggested by Lipkus, ${ }^{16}$ female respondents were asked to estimate their own lifetime breast or ovarian cancer risk, and males were asked to estimate a female relative's lifetime risk of developing these types of cancers, compared with others of their same race and age, indicating if they thought their risk (or a family member's risk) was higher, the same, or lower. We used a modification of Schwartz et al. s $^{17}$ three-item measure of numeracy previously used in a study of screening for mammography.

\section{APPROACH AND ANALYSIS}

The statistical analysis for this study used SPSS version 12.0 (SPSS, Chicago, IL). The data set provided to us by Harris included propensity score weighting for age, sex, race/ethnicity, education, region, and household in order to bring data in line with respondents' propensity to be online (based on the US Census Bureau's 2012 Current Population Survey). In stage 2, Harris uses back-end weighting with the collected data. Harris' two-stage approach of sampling and weighting was used to ensure the data represented the US national population. Additionally, we used the SPSS option for weighted data in our analyses.

Descriptive statistics for categorical variables were provided as proportions. The $\chi^{2}$ test was used to compare the background characteristics between respondents who were aware and not aware of the story, correctly recalled Jolie's estimated risk of breast cancer, and answered questions about the $B R C A$ mutation and breast cancer risks. In determining any differential impact of story awareness on health-related behaviors during the 3 weeks following the story, group differences were examined by statistically controlling for numeracy and family history.

\section{RESULTS}

Almost three quarters of sampled adults (74\%; $n=1,907)$ correctly indicated that Angelina Jolie had undergone a double mastectomy to reduce her risk of developing breast cancer (question 1 in the Supplementary Appendix online). Significant differences in awareness existed across sociodemographic groups (Table 1) with higher recall of the story among 
women and whites and lower recall among younger, unmarried, less affluent, less educated, and numerate respondents. There were no significant differences in story awareness evident in regard to geographical region and family history of cancer.

Respondents were asked what Jolie's risk of developing breast cancer was (item 3 in the Supplementary Appendix online). Among respondents aware of the story, almost half (47\%) reported her risk within a reasonable range (80-90\%) of Jolie's disclosed estimated risk of $87 \%$. Correct recall was higher among women, nonminorities, wealthier, and older respondents, including those who had been divorced, separated, or widowed and those who had higher numeracy scores (see Table 1).

Among respondents who accurately reported Jolie's estimated risk, fewer than $10 \%$ had the information necessary to interpret Ms Jolie's risk of developing cancer relative to a woman unaffected by the BRCA gene mutation. To investigate this question, we asked respondents to indicate the proportion of breast cancer cases for which a $B R C A$ gene mutation is responsible (correct response less than 10\%) and the average woman's risk of getting breast cancer over her lifetime if she does not have a BRCA mutation (correct response between 5 and 15\%) (items 5 and 6 in the Supplementary Appendix online). Slightly more than one in five respondents $(22.6 \% ; n$ $=206)$ correctly reported the contribution of $B R C A$ mutations to all breast cancer cases, and $31.2 \%(n=284)$ knew an average woman's risk; $8.9 \%(n=81)$ correctly answered both questions.

We also explored the extent to which individuals who did not recall Jolie's risk responded to the two knowledge questions; $19.9 \%(n=198)$ correctly answered the BRCA mutation question; $31.6 \%(n=315)$ correctly answered the average risk question; and $5.8 \%(n=58)$ correctly responded to both questions, and this number was significantly lower than the group with correct recall of Jolie's risk $(P<0.02)$.

For the overall survey sample, $7.9 \%$ of respondents correctly answered both questions (Table 1, column 4). Individuals were less likely to correctly respond to the $B R C A$ mutation question than the question about average risk, $23(n=583)$ compared with $31 \%(n=794)$, respectively. Interestingly, men were significantly more accurate in their knowledge of this information than women, as were better educated and more numerate respondents, as well as those from the Western and Midwest geographic regions. Lower knowledge rates were reported by the individuals who had been divorced, separated, or widowed. Notably, family history of breast and ovarian cancer was not related to more accurate knowledge of cancer risks (Table 1).

We further explored the relationship between family history and an individual's rating of one's own or family member's risk of dying from breast or ovarian cancer compared with the average population risk for others of the same race and age, stratified by awareness of the Jolie story. We found that individuals aware of the story and who reported at least one affected firstdegree relative were less likely to rate their personal risk as higher than the population average relative to those who had similar family health histories and did not know the story (39 vs. 59\%; $P<0.05)$. Perhaps even more striking and worrisome is that about half of all individuals aware of the story and without a family history of cancer rated their cancer risk as lower than the population average relative to those without a family history and unaware of the story ( 47 vs. $52 \%$, but the difference was not statistically significant). There were no sex differences in these associations.

Although the story was widely reported, only $3.4 \%$ of the respondents who were aware of the story indicated that they had read Ms Jolie's commentary originally in The New York Times. Most respondents became aware of the story though a national or local television news story $(61.2 \%)$ or entertainment piece (21.5\%). A quarter (25.7\%) of respondents reported exposure to the story from two or more information sources.

We assessed attitudes toward the story by asking respondents what they thought and felt after hearing about Jolie's story by indicating with which of eight close-ended statements about the story they agreed (item 4 in the Supplementary Appendix online). Almost three-fourths (72\%) of both men and women felt Ms Jolie did the right thing by publically announcing her medical situation. However, more women than men felt she did the right thing in having the surgery (73.5 vs. $65.7 \%$, respectively; $P<0.002$ ). More than half of the women (57.4\%) said that they would have undergone the surgery themselves if they carried the "faulty" gene. Half of the women (49.9\%) said they would recommend the surgery to a family member under those circumstances; in contrast, only $40.0 \%$ of men would make that recommendation to a family member carrying the gene $(P<0.0001)$. Both males and females reported considering or encouraging a family member to get genetic testing to test for the faulty breast cancer gene at about the same rate ( $8.9 \%$ for women and $9.1 \%$ for males).

Some respondents ( $7.8 \%$ for women and $8.9 \%$ for males) indicated that the story had resulted in heightened anxiety about their own or a family member's risk of developing cancer, whereas $\sim 5 \%$ (4.6\% for women and $4.7 \%$ for males) said that the story made them less anxious about cancer risks; there are no sex differences in these items. More women (9\%) than men $(4.9 \%)(P<0.004)$ indicated that the story made them feel more motivated to do something about their health such as seeing a doctor, having a mammogram, or seeing a genetic counselor.

All respondents were asked if they took any health-related action over the past 3 weeks (the time span which included Ms Jolie's public disclosure). Although the majority of respondents (80\%) did not endorse any of the options listed (see item 9 in the Supplementary Appendix online), a subset appeared to have initiated story-related behaviors of some kind. For instance, $6.6 \%$ had a mammogram and/or encouraged a family member to have a mammogram, $6.4 \%$ indicated that they had learned more about breast or ovarian cancer from talk shows on television or radio, etc., $6.4 \%$ reported seeking information about insurance coverage for genetic testing, and 5.8\% indicated that they talked with relatives about their family history of cancer. Very few participants indicated that they looked for information about genetic tests for breast or ovarian cancer through the Internet $(2.7 \%)$, spoke with a doctor $(2.0 \%)$ or a 
Table 1. Percentages of sociodemographic variables, numeracy, and personal and family risk of cancer predicting awareness, recall, and knowledge $(N=2,572)^{\text {a }}$

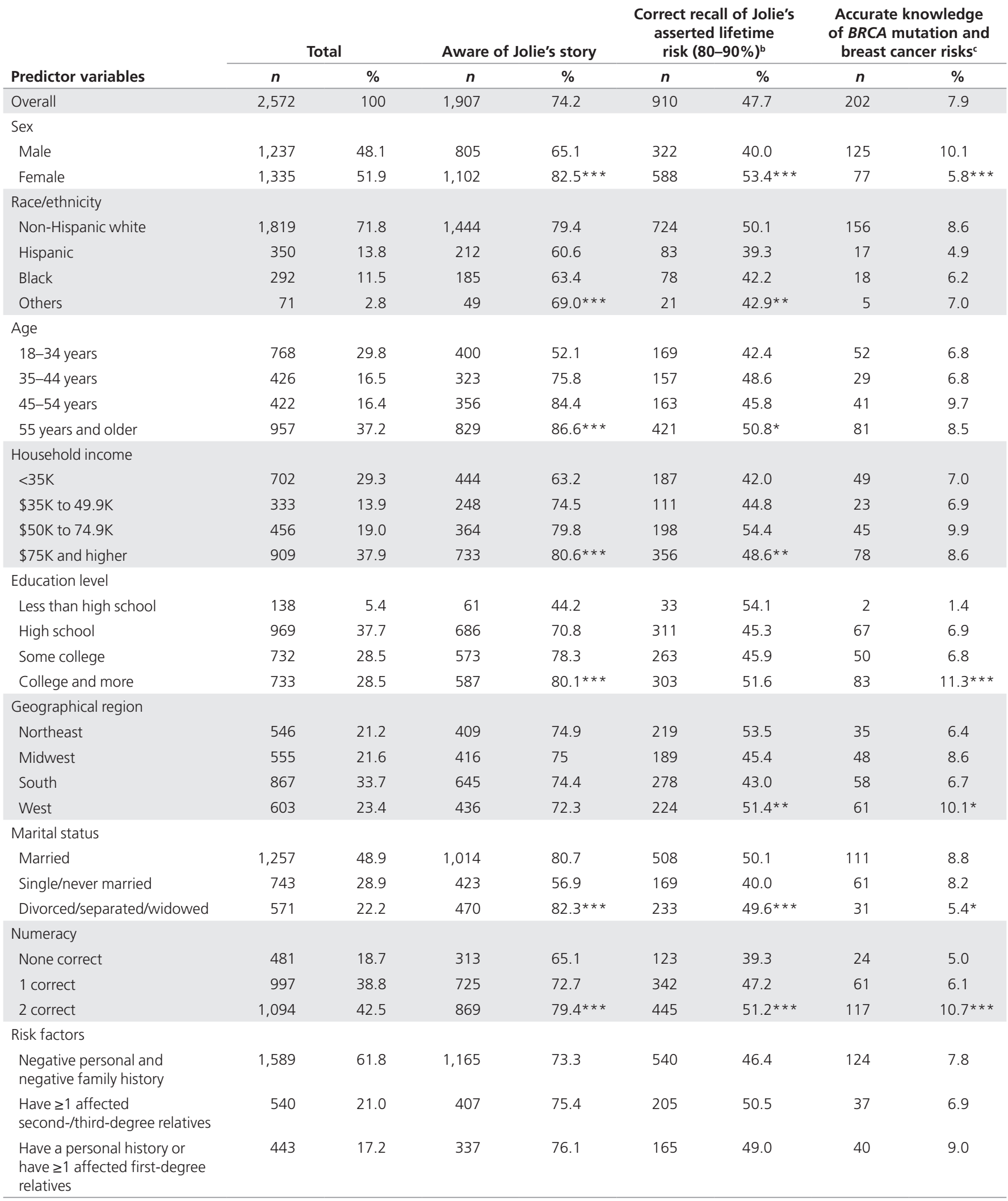

aResults were calculated after the application of poststratification weights so that the sample would be representative for the US population according to the

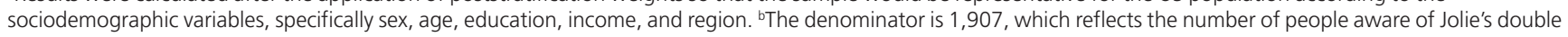
mastectomy news story. The denominator is 2,572 , the entire survey sample. ${ }^{*} P<0.05 ;{ }^{*} P<0.01 ;{ }^{*} * P<0.001$. 
genetic counselor (1.3\%), and sought information about insurance coverage and costs for preventive surgery (1.5\%) or about their cancer risk.

There was a positive association between respondent endorsement of positive attitudes toward the Jolie's story and an indication of positive health actions in the past 3 weeks (Pearson correlation of $0.25 ; P<0.0001$ ); nevertheless, endorsement of the behaviors did not differ between respondents who were aware or not aware of the story, after controlling for demographic variables, numeracy, and personal and family history.

\section{DISCUSSION}

Based on our population sample, we estimate that three of every four American adults were aware of Angelina Jolie's prophylactic mastectomy, and almost half could recall Jolie's estimated risk of breast cancer before surgery. Nevertheless, fewer than $10 \%$ of all respondents had sufficient information necessary to interpret the information about Ms Jolie's risk of developing breast cancer relative to women unaffected by the BRCA gene mutation.

Awareness of the Jolie story was not associated with greater knowledge of breast cancer risk, with or without consideration of the BRCA gene mutation. In fact, among those who followed the story, women were less accurate than men, almost always overestimating the contribution of the $B R C A$ mutation to breast cancer and the average women's lifetime risk of breast cancer.

We investigated whether awareness of Jolie's story was associated with respondents ability to more accurately relate their own family history to their own (or family member's) cancer risk and found that there were substantial errors evident; about half thought that lack of family history was associated with lower than average risk of cancer while it also appeared that individuals aware of the story, and with at least one cancer-affected firstdegree relative, were less likely to rate their own (or family member's) cancer risk higher than average. These findings suggest that respondents largely interpreted a negative family history as protective against cancer and that exposure to the story appeared to confuse, rather than clarify, an understanding of the relationship between a positive family history and increased cancer risk.

It is noteworthy that more than $8 \%$ of the population reported some increased anxiety in the weeks following the story. Both men and women overwhelmingly approved of Angelina going public with her story; however, more women than men approved of her decision to have prophylactic surgery or said that they would recommend the surgery to a family member if they carried the mutation. Indeed, $57 \%$ of women said that they would have undergone the surgery themselves if they carried the "faulty" gene.

As a point of perspective, a 2008 survey of US women with a $B R C A$ mutation found that $36 \%$ had opted for the prophylactic bilateral mastectomy, the highest uptake rate for this surgery in the world. ${ }^{18}$

Men have a role in this story. They have and help frame opinions and provide support to women about medical decisions, as the popular media suggested about Jolie's partner Brad Pitt. Clinicians' attitudes and advice toward prophylactic mastectomy may also vary by gender; a recent European study found that male general practitioners were less positive than female practitioners toward recommending prophylactic mastectomy for women who carry a $B R C A$ mutation. ${ }^{19}$

While $9 \%$ of women reported feeling motivated to do something they were putting off as a result of the story, like having a mammogram or seeing a doctor or a genetic counselor, there was little evidence that they acted on these intentions, at least not in the 3 weeks immediately following the story. This is consistent with outcomes of a previous mass media campaign by Myriad Genetics to promote BRCA1/2 testing, which resulted in a short-term increase in inquiries, but little evidence of population-level changes in discussions with healthcare providers or testing increases. ${ }^{20,21}$

Awareness of the Jolie story was notably much higher than reported awareness of the previously mentioned Myriad campaign ( 74 vs. $36 \%) .{ }^{20}$ Celebrities can successfully raise awareness about a health issue, but it is a greater challenge for health journalists to ensure accurate understanding. ${ }^{22}$ This is difficult when the issue involves an understanding of risk and probabilities as is true of the genetic information that Angelina Jolie communicated. In this regard, approximately one-third of our respondents $(31.7 \%)$ incorrectly predicted how many times a coin would come up heads in 1,000 coin flips. This is indicative of quantitative skill deficits found for almost half of the Americans who are characterized as functioning at below basic $(22 \%)$ or basic (33\%) quantitative skill levels. ${ }^{23}$ The 2002 mass media campaign about $B R C A 1 / 2$ testing resulted in increased awareness but not knowledge and was accompanied by a greater proportion of testing inquiries by women who were not at high risk for a BRCA 1/2 mutation. ${ }^{21,24}$ It is not surprising that while Angelina Jolie's health story heightened awareness of breast cancer, it did not help the public (even the subset with greater risk due to family history) to better understand the risks of the disease for the vast majority of women who do not have a $B R C A$ mutation.

A strength of this study is the immediacy and reach of the data collection. The online survey was fielded over 2 days within 3 weeks of the media story about Ms Jolie; it included 2,572 adults (aged 18 years and older) and was conducted by Harris Interactive. In their approach, Harris ensures a representative sample that also includes a propensity score for using the Internet. But, propensity scores do not account for all the variation from this sample to the overall United States. For example, $17.2 \%$ of our respondents reported either a personal history of breast or ovarian cancer or a similar history in a first-degree relative; we would expect that figure to be closer to $10 \%$ in a national sample, indicating that respondents who chose to do this survey have a greater personal or close family history of relevant cancers compared to the overall population. ${ }^{25,26}$

To facilitate rapid implementation of the survey, we were restricted in the number and format of the questions asked, and the survey was largely restricted to multiple choice options. As a result, nuanced aspects of this story are lost.

We also made a choice regarding the range of cancer risks considered to be "accurately" reported. Hereditary cancer risks are generally presented as ranges, to represent the existing 
uncertainty in the scientific literature. Risks for breast cancer for women with a mutation in the BRCA1 gene have been reported to range from 44 to $87 \%$ by the age of 70 years. ${ }^{27,28}$ While we do not know the exact risk figures reported to Ms Jolie by her genetic counselor, we do know that she chose to report an $87 \%$ risk in her commentary. As this work was on awareness and recall of celebrity revelations, we focused on a range (80-90\%) close to the specific risk provided in Ms Jolie's New York Times piece.

One problem with the survey is that it failed to allow nonwhole-number responses. The correct answer to one of the three numeracy questions used in our measure was a decimal $(0.1 \%) .{ }^{17}$ As some respondents may have known that 0 was incorrect, they may have entered 1 as the smallest number that was acceptable. On the other hand, respondents may have thought the answer was $1 \%$. As we cannot tell the right answers from the wrong on this item, we decided to drop that question and use the other two questions as our numeracy indicator. We think the measure was nonetheless useful as it provided a somewhat more sensitive measure of population function relative to numeric concepts than educational level.

As our understanding of the genetic contribution to disease risk continues to unfold, it will be vital for health journalists to seek out clinical and scientific experts who can communicate population risks in ways that inform, rather than alarm. It is recommended that clinicians seek ways to reach the most vulnerable and high-risk populations with clear and useful information. ${ }^{4,10,22}$ Preparing for inevitable future events similar to the Angelina Jolie's announcement involves transforming heightened public awareness into heightened public understanding and appropriate use of medical resources.

\section{SUPPLEMENTARY MATERIAL}

Supplementary material is linked to the online version of the paper at http://www.nature.com/gim

\section{ACKNOWLEDGMENTS}

We acknowledge the funding for this project from the Johns Hopkins Center for Genomic Literacy and Communication and the Department of Health, Behavior, and Society (faculty discretionary account) of the Johns Hopkins Bloomberg School of Public Health.

\section{DISCLOSURE}

The authors declare no conflict of interest.

\section{REFERENCES}

1. Cram P, Fendrick AM, Inadomi J, Cowen ME, Carpenter D, Vijan S. The impact of a celebrity promotional campaign on the use of colon cancer screening: the Katie Couric effect. Arch Intern Med 2003;163:1601-1605.

2. Beck CS, Aubuchon SM, McKenna TP, Ruhl S, Simmons N. Blurring personal health and public priorities: an analysis of celebrity health narratives in the public sphere. Health Commun 2013.

3. Chapman S, McLeod K, Wakefield M, Holding S. Impact of news of celebrity illness on breast cancer screening: Kylie Minogue's breast cancer diagnosis. Med J Aust 2005;183:247-250.

4. Larson RJ, Woloshin S, Schwartz LM, Welch HG. Celebrity endorsements of cancer screening. J Natl Cancer Inst 2005;97:693-695.

5. Kelaher M, Cawson J, Miller J, et al. Use of breast cancer screening and treatment services by Australian women aged 25-44 years following Kylie Minogue's breast cancer diagnosis. Int J Epid 2008; $37: 1326-1332$

6. Nattinger AB, Hoffmann RG, Howell-Pelz A, Goodwin JS. Effect of Nancy Reagan's mastectomy on choice of surgery for breast cancer by US women. JAMA 1998;279:762-766.

7. Brown WJ, Basil MD. Media celebrities and public health: responses to 'Magic' Johnson's HIV disclosure and its impact on AIDS risk and high-risk behaviors. Health Commun 1995; 7:345-370.

8. Kreps GJ. The impact of communication on cancer risk, incidence, morbidity, mortality, and quality of life. Health Commun 2003;15:161-169.

9. Niederdeppe J. Beyond knowledge gaps: examining sociodemographic differences in response to cancer news. Human Communication Research. 2008:34:423-447.

10. Dentzer S. Communicating medical news - pitfalls of health care journalism NEJM 2009;360:1-3.

11. Greenslade R. Angelina Jolie illustrates the virtues of celebrity power. The Guardian 2013. http://www.guardian.co.uk/media/greenslade/2013/may/15/ angelinajolie-breast-cancer. Accessed 10 July 2013.

12. HINTS 2005. HINTS Instrument. http://hints.cancer.gov/docs/HINTS_2005 Instrument-English.pdf. Accessed 14 September 2013.

13. Gail MH, Brinton LA, Byar DP, et al. Projecting individualized probabilities of developing breast cancer for white females who are being examined annually. J Natl Cancer Inst 1989;81:1879-1886.

14. Claus EB, Risch N, Thompson WD. Autosomal dominant inheritance of earlyonset breast cancer. Implications for risk prediction. Cancer 1994;73:643-651.

15. Berliner JL, Fay AM, Cummings SA, Burnett B, Tillmanns T. NSGC practice guideline: risk assessment and genetic counseling for hereditary breast and ovarian cancer. J Genet Couns 2013;22:155-163.

16. Lipkus IM, Kuchibhatla M, McBride CM, et al. Relationships among breast cancer perceived absolute risk, comparative risk, and worries. Cancer Epidemiol Biomarkers Prev 2000;9:973-975.

17. Schwartz LM, Woloshin S, Black WC, Welch HG. The role of numeracy in understanding the benefit of screening mammography. Ann Intern Med 1997;127:966-972

18. Metcalfe KA, Birenbaum-Carmeli D, Lubinski J, et al.; Hereditary Breast Cancer Clinical Study Group. International variation in rates of uptake of preventive options in BRCA1 and BRCA2 mutation carriers. Int J Cancer 2008;122:2017-2022.

19. Den Heijer $\mathrm{M}$, van Asperen $\mathrm{CJ}$, Harris $\mathrm{H}$, et al. International variation in physicians' attitudes towards prophylactic mastectomy - comparison between France, Germany, the Netherlands and the United Kingdom. Eur J Cancer. 2013 doi:pii: S0959-8049(13)00359-6. 10.1016/j.ejca.2013.04.025 (Epub ahead of print).

20. Centers for Disease Control and Prevention (CDC). Genetic testing for breast and ovarian cancer susceptibility: evaluating direct-to-consumer marketing-Atlanta, Denver, Raleigh-Durham, and Seattle, 2003. MMWR Morb Mortal Wkly Rep. 2004;53:603-606.

21. Bowen DJ, Harris J, Jorgensen CM, Myers MF, Kuniyuki A. Socioeconomic influences on the effects of a genetic testing direct-to-consumer marketing campaign. Public Health Genomics 2010;13:131-142.

22. Larsson A, Oxman AD, Carling C, Herrin J. Medical messages in the mediabarriers and solutions to improving medical journalism. Health Expect 2003;6:323-331.

23. Kutner M, Greenberg $E$, Jin $Y$, Paulsen C. The Health Literacy of America's Adults: Results From the 2003 National Assessment of Adult Literacy (NCES 2006-483). U.S. Department of Education, National Center for Education Statistics: Washington, DC, 2006.

24. Mouchawar J, Hensley-Alford S, Laurion S, et al. Impact of direct-to-consumer advertising for hereditary breast cancer testing on genetic services at a managed care organization: a naturally-occurring experiment. Genet Med 2005;7:191-197.

25. Hall IJ, Burke W, Coughlin S, Lee NC. Population-based estimates of the prevalence of family history of cancer among women. Community Genet 2001:4:134-142.

26. Howlader N, Noone AM, Krapcho M, Garshell J, Neyman N, Altekruse SF, et al, SEER Cancer Statistics Review, 1975-2010, National Cancer Institute: Bethesda, MD. http://seer.cancer.gov/csr/1975_2010/. Accessed 14 September 2013.

27. Antoniou A, Pharoah PD, Narod S, et al. Average risks of breast and ovarian cancer associated with BRCA1 or BRCA2 mutations detected in case series unselected for family history: a combined analysis of 22 studies. Am J Hum Genet 2003;72:1117-1130.

28. Mavaddat N, Peock S, Frost D, et al.; EMBRACE. Cancer risks for BRCA1 and BRCA2 mutation carriers: results from prospective analysis of EMBRACE. J Nat/ Cancer Inst 2013;105:812-822. 